\title{
Metabolic disease in Nepal: A perspective
}

\author{
Pandey $\mathrm{AS}^{1}$
}

${ }^{1}$ Department of Biochemistry

Kathmandu Medical College of Basic Sciences, Bhaktapur, Nepal

\section{Corresponding author}

Arti S Pandey

Department of Biochemistry

Kathmandu Medical College of Basic Sciences, Bhaktapur, Nepal

Email: rtpandey@yahoo.com

Kathmandu Univ Med J 2010;8(31):333-40

\begin{abstract}
Inborn errors of metabolism or metabolic diseases, are a group of genetically determined metabolic disorders that result in mental retardation or early death. The prevalence of IEM in various countries shows a prevalence varying between 1 in 800 to 1 in 5000 . As the technology for detecting metabolites has become more advanced, studies utilizing more modern methods report a higher prevalence. There have been reports of a few Inborn errors of metabolisms in Nepal, but studies to gauge the prevalence of these disorders in the Nepalese population are lacking. With conflicting statistical numbers from different sources regarding mental retardation cases in Nepalese population and a substantial rate of consanguinity and inter caste marriages, it would be prudent to initiate some pilot studies to estimate the prevalence of a group of disorders that can be diagnosed through simple laboratory tests, to be followed by a screening programme depending upon the results. The presented review discusses the need for and the possibilities of screening for these errors for early intervention in Nepal.
\end{abstract}

\section{Key Words}

consanguinity, genetic disease, inborn errors, metabolic disease, mental retardation

\section{INTRODUCTION}

e Molecular basis of Inborn Errors of Metabolism (IEM) / Metabolic Disease. e term "Inborn Errors of Metabolism" (IEM),represents a group of inherited disorders that result in the impaired activity of an enzyme, a structural protein or a transporter molecule. e underlying causes of IEMs are mutations in genes that code for proteins, resulting in a dysfunctional or structurally altered protein, causing a block in a metabolic pathway. ese dysfunctional proteins may be the enzymes required for the metabolism of carbohydrate, proteins or lipids, resulting in disorders associated with altered or blocked metabolism of these biomolecules. is results in the accumulation of abnormal metabolites proximal to the block or the lack of products of the reaction that is blocked. For example

\section{$\mathrm{A} \Rightarrow \mathrm{B} \Rightarrow \mathrm{C} \Rightarrow \mathrm{D}$}

A block due to the de ciency of the enzyme converting $B$ to $C$ will result in excess of $B$ and a lack of $C$, either of which can manifest as disease. A restriction of the precursor of $\mathrm{B}$ (i.e. A in the above example) or a supply of the product C, are potential therapeutic interventions. us, about half of the over about a thousand of known metabolic disorders can be treated biochemically . e medical consequences of IEMs vary from a failure to thrive to acute illness that can lead to brain damage, coma and death. Some examples of these enzymatic de ciencies associated with common metabolic disorders are shown in Table 1. 
Table 1. Selected Metabolic disorders with major associated symptoms

\begin{tabular}{|c|c|c|}
\hline Disorder & Enzyme Deficiency & Symptoms \\
\hline \multicolumn{3}{|c|}{ Disorders of Carbohydrate Metabolism } \\
\hline Galactosemia: & Galactose $1 \mathrm{P}$ uridyl transferase & Liver failure, mental retardation \\
\hline Mucopolysaccaridoses: & Glycosaminoglycans degrading enzymes & $\begin{array}{l}\text { Accumulation of GAGS in tissues resulting in hepatomegaly/ } \\
\text { splenomegaly/disturbances of growth/coarse facies/mental } \\
\text { retardation }\end{array}$ \\
\hline Glycogen storage disorders & Enzymes of glycogen metabolism & $\begin{array}{l}\text { Deposition of abnormal type or quantity of glycogen in tissues, } \\
\text { liver or heart failure }\end{array}$ \\
\hline \multicolumn{3}{|c|}{ Disorders of amino acid metabolism } \\
\hline Phenylketonuria & Phe Ala hydroxylase & Retarded development and neurological abnormalities \\
\hline Hyperglycinemia & Glycine cleavage enzyme & Failure to suck, coma, myoclonic jerks, Ochronosis \\
\hline Homocystinuria: & Cystathione beta synthase & Thrombosis, osteoporosis, dislocated lens, mental retardation \\
\hline Maple syrup urine disease: & alpha ketoacid decarboxylase & Development delay, convulsions in later infancy, low IQ \\
\hline Tyrosinemia: & Fumarylacetoacetate hydrolase & $\begin{array}{l}\text { Diarrhoea, vomiting, "cabbage like" odor, liver failure, renal } \\
\text { tubular dysfunction }\end{array}$ \\
\hline \multicolumn{3}{|l|}{ Organic acidemias } \\
\hline Methylmalonic acidurias & Methylmalonyl CoA mutase/ Vit. B12 & Severe acidosis, multiple organ failure \\
\hline Propionic academia & Propionyl CoA carboxylase & Metabolic acidosis, seizures, coma \\
\hline Isovaleric academia: & Isovaleryl CoA dehydrogenase & "sweaty feet" odor, seizures, coma \\
\hline Glutaric academia Type I & Glutaryl CoA dehydrogenase & Spasticity, dystonia, seizures, coma \\
\hline \multirow{5}{*}{ Hyperammonemias } & $\begin{array}{l}\text { Enzymes of Urea CycleCarbamoyl Phosphate } \\
\text { synthase }\end{array}$ & Hyperammonemia, encephalopathy, coma, death \\
\hline & Ornithine carbamoyl transferase & \\
\hline & Argininosuccinate synthase & \\
\hline & Argininosuccinate lyase & \\
\hline & Arginase & \\
\hline Fatty acid oxidation disorders & Medium chain acyl coA dehydrogenase & $\begin{array}{l}\text { Acidosis, } \\
\text { hypoglycemia,encephalopathy, hepatomegaly, microvesicular } \\
\text { fatty infiltration of the viscera }\end{array}$ \\
\hline \multicolumn{3}{|l|}{ Lysosomal storage disorders } \\
\hline Tay-sachs disease: & Hexosaminidase $\mathrm{A}$ & Hepatomegaly, mental and neurological deterioration, death \\
\hline Pompe's disease: & Lysosomal alpha 1-4 or alpha 1-6 glucosidase & Cardiomegaly and cardiac failure \\
\hline
\end{tabular}

\section{PREVALENCE}

e majority of metabolic disorders have autosomal recessive inheritance, a few though, show X-linked inheritance. e frequency of a ected births in a population with random (non-consanguineous) mating may be calculated from the frequency of carriers by using the formula

Frequency of a ected births $=[0.25$ (frequency of heterozygotes)2]. ${ }^{1} \quad$ ere are likely to be signi cant geographical di erences in the incidence of individual inborn errors of metabolism. In areas where there is a high rate of consanguineous marriage, there will be higher incidence of metabolic disease overall.

Although individual inborn errors of metabolism are relatively rare conditions, as a group they represent a vast and diverse collection of diseases that are a signi cant cause of morbidity and mortality worldwide. Even though reports in the literature o en quote a cumulative incidence varying between 1 in 1500 and 1 in 5000 live births, a recent retrospective study ${ }^{2}$ on an ethnicallydiverse population in the United Kingdomfound this range to underestimate the real gure, and placed the prevalence of inherited metabolic disorders at 1 in 784 live births. Data for the prevalence of IEMs in South Asia is starting to come in. A study undertaken in India 3 indicates an incidence of 1 in every 1000 newborns. Another study from Pakistan ${ }^{4}$ that tested undiagnosed children $<1-10$ years showing neurological symptoms, development delay and vomiting, found $26 \%$ of the children to have one of the tested IEMs. A similar study in China found $48.6 \%$ of the 4981 pediatric patients suspected of metabolic disease to have aminoacidurias, organic acidemias or fa $4 y$ acid disorders. ${ }^{5} \quad$ e measured incidence in a particular area depends on the methods used for screening, with older and less sensitive biochemical methods showing a much lower incidence compared to the methods employing the more speci $c$ tandem mass spectrometry. 
In Nepal, Wilson's disease, an inborn error of copper metabolism has been documented twice as case reports. ${ }^{6,7}$ Although studies have been conducted on the incidence of chromosomal disorders, ${ }^{8}$ inborn errors of metabolism, probably because of their rarity, have not caught a tention.

ere has been a case report on -thalassemia ${ }^{9}$ along with earlier studies done in the 1960s, that found some cases of -thalassemia, a few cases of the presence of abnormal hemoglobins $\mathrm{H}$ and $\mathrm{E}$, and Glucose 6 phosphate dehydrogenase de ciency $^{10}$ in Nepal.

\section{DIAGNOSTICS}

In many countries, newborn screening for a few inherited metabolic diseases like hypothyroidism, phenylketonuria and sickle cell disease is a routine part of neonatal care. e primary aim of neonatal screening is the early detection and treatment of clinically important disorders in order to minimize morbidity and mortality. Infants with inborn errors of metabolism appear normal at birth as most of the accumulating abnormal metabolited can cross the placenta and can be cleared by the mother. e initial ndings are usually those of lethargy and poor feeding, seen in almost any sick infant. An infant in whom these go unnoticed may come to a tention because of apnea or sudden respiratory distress. Signs of Central Nervous System dysfunction, such as seizures and abnormal muscle tone, may also be noted. ${ }^{11}$

e clinical diversity that these disorders present makes it di cult to recognize them clinically, with speci c diagnosis being extremely dependent on laboratory diagnosis. ${ }^{12,13}$ Within inborn errors of metabolism diagnosis programs, biochemical screening procedures are of fundamental importance, as these serve as a rstindication of the general metabolic routes that the alterations can be involved in, and the more speci $c$ tests needed for proceeding with the evaluation. ${ }^{14}$ Simple laboratory tests, including measurement of blood gases, electrolytes, glucose, lactate, ammonia and basic urinalysis o en provide the initial clues to possible metabolic disease. Although the presence of a speci $c$ inborn error of metabolism cannot be con rmed until biochemical genetic laboratory results are available, a diagnosis may be suspected and an inborn disease category reasonably hypothesized on the basis of ndings from simple biochemical/clinical laboratory studies and the clinical presentation. ${ }^{15}$ Such an initial hypothesis is important, because the physician must initiate appropriate therapy without delay and without a nal diagnosis, to decrease the morbidity or mortality associated with these conditions.

e ideal method of diagnosing metabolic disorders is through Electrospray Tandem Mass Spectrometry where a single test can screen for a wide range of disorders. e detection rates of faty acid oxidation disorders, some of which are lethal, have been found to increase with this method. ${ }^{16}$ e method is highly sensitive, but quite expensive. In addition, it requires specialized training in the use of the spectrometer as well as an expertise in the understanding of a large number of inborn errors of metabolism. In countries like UK, where newborn screening for several diseases like phenylketonuria, cystic brosis and Duchene's muscular dystrophy have been carried out for some years, the screening for other disorders through Tandem Mass is recommended. ${ }^{1}$ In a country like Nepal, the high cost of carrying out Tandem Mass spectroscopy paired with a complete lack of knowledge of the incidence of inborn errors of metabolism would make this a very irrational choice.

\section{IEMs in the Nepalese context}

\section{Mental Retardation}

Screening of newborns for metabolic disorders is carried out in many countries in Europe, America and Asia. is includes screening for phenylketonuria, cystic brosis, hypothyroidism (though not strictly a metabolic disorder) and thalassemias. Technological advances in diagnosis led to identi cation of more of these disorders, which had escaped detection with older methods.

In Nepal, the earliest study done to detect IEMs was a part of a larger study carried out in India, Bangladesh, Pakistan, Nepal, Bhutan and Sri Lanka. ${ }^{10}$ e study limited itself to hemoglobinopathies and related disorders, and the Nepalese population that was tested comprised of Gurkhas and Sherpas residing outside Nepal. One in approximately 130 screened Nepalese were found to be thalassemia trait carriers. In a 2009 study done at BPKIHS genetic clinic, ${ }^{8}$ 10 of 30 children with mental retardation, dysmorphic features, short stature and ambiguous genitalia, were found to have chromosomal disorders. e study concluded that in the remaining 20 children, either the aberrations were undetectable by the available technology, or could have been the result of other single gene disorders. It is reasonable to speculate that some of these undiagnosed cases of mental retardation could have been the result of metabolic disorders. A survey of self-reported disability in Eastern Nepal found a rate of disability of $4.87 \%$, of which $17.1 \%$ is reported to be a result of an "inborn syndrome". ${ }^{17}$ It is logical to assume that these "inborn syndromes" are a combination of cytogenetic and metabolic disorders.

e Nepal country health system pro le shows a prevalence of disabilities of $1.63 \%$ out of which $5.9 \%$ are mental retardation. ${ }^{18}$ A 1989 survey done by "Maryknoll 
Father's Project" found a prevalence of mental retardation of $4.1 \%$ amongst Nepalese population. ${ }^{19}$ A survey of two developing towns in western Nepal in 1998 revealed a high point prevalence $(35 \%)$ of "conspicuous psychiatric morbidity" ${ }^{20}$ According to Dr. Kan Tun ${ }^{21}$, a former World Health Organization representative to Nepal, around $1 \%$ of the Nepalese population has severe mental illness and $10-20 \%$ milder mental health problems. A population of around 29 million hence puts the number of severely mentally ill at 290,000 and mildly mentally ill at 2,900,000 to $5,800,000$. It is again logical to assume that a considerable number of these estimates might be the surviving cases of inborn errors of metabolism, most of which result in mental retardation.

\section{Consanguinity}

It is established that the incidence of inborn errors is higher in areas with higher rates of consanguinity. ${ }^{2}$ Anthropological studies undertaken by Fricke and his colleagues in the Timling region of Nepal ( alongTibet and Burmese borders) report that cross cousin marriages are common and part of the social structure that is strongly based on kin alliance with reciprocal rights and obligations. ${ }^{23,24}$ In rural areas in Nepal where farming and manual labour are predominant occupations, cross cousin marriages also have an economic value as the boundaries of endogamy are shaped by family allegiances and reciprocal rights and obligations. ${ }^{24}$ Amongst the Hindus of Nepal, the common form of consanguineous marriages is patrilateral cross cousin marriages. ${ }^{25}$ Endogamy has been prevalent in communities like Magars, Gurungs, Tamangs and others where the members of the communities marry among their own near relations. ${ }^{26}$ ere is still the popular local version i.e. MamcheliPhuphuchela which means the sister's son would be married to the brother's daughter.

is system was also adopted among the ruling families of Shahs and Ranas. ${ }^{26}$

\section{Caste system and recessive disease}

Populations arising from "founder e ects" have a limited gene pool to begin with. For example, in a recent study on Indian population history, ${ }^{27}$ it was found that two ancient populations, genetically divergent, are ancestral to most Indians today. One the Ancestral North Indians (ANI) is genetically close to Middle Easterners, Central Asians and Europeans, whereas the other the "Ancestral South Indians" (ASI) is as distinct from ANI and East Asians as they are from each other. Allele frequency di erences between groups re ect strong founder e ects whose signatures have been maintained for thousands of years owing to endogamy. e authors hence predicted that there will be an excess of recessive diseases in India, which should be possible to screen and map genetically.

ey proposed that founder e ects are responsible for an even higher burden of recessive diseases in India than consanguinity. ${ }^{27}$ Political scientists Joshi and Rose broadly classify the Nepalese population into three major ethnic groups in terms of their origins: Indo-Nepalese, TibetoNepalese and indigenous Nepalese. ${ }^{28}$ e genetic diversity of populations inhabiting an area is also in uenced by the geographic and physical features encompassing the region. Whereas the Hindu Kush Mountains and the arid deserts in Iran have served as obstacles to gene ow, the Nile River Valley, the strait of Babel Mandeb and Beringia are examples of natural passageways for the migrations of modern humans. e Himalayan range, in addition to being a formidable barrier, provides for dramatically diverse climatic conditions on either side of it. ${ }^{29}$ An investigation of the genetic a nities of Newar, Tamang and people from cosmopolitan Kathmandu and Tibet ${ }^{29}$ suggests that the Tibetans and Nepalese are in part descendants of TibetoBurman speaking groups originating from Northeast Asia. With the exception of Tamang, both Newar and the people of cosmopolitan Kathmandu exhibit considerable similarities to the Indian $Y$ haplogroup distribution.

Although the conclusion from the above can only be implied, the gene pool of the Nepalese populations se tled in various geographically distinct areas was probably limited, both due to founder e ects as well as the presence of the Himalayas as a barrier to gene ow. ese populations have over time, come to be known as di erent castes or Janajatis.

e de nition of caste system most relevant to $\mathrm{Nepal}^{30}$ is "castes are ranked endogamous divisions of society in which membership is hereditary and permanent".31

Nepali caste rules normally prescribe isogamy for its members. Such marriages are held lawful for the inheritance of property by the o spring and for ensuring ritual purity of a caste-member. Caste endogamy is thus held sacrosanct because heredity is basic to the concept of caste-purity. e Newar have a highly structured caste system, which the Malla kings dictated over 600 years ago. Although old caste restrictions on occupation are gradually fading, the social restrictions of the caste system are still largely observed and the Newar rarely marry outside their caste. $^{32}$ ere is no data available in Nepal regarding the e ect of caste system on recessive disease. Studies from neighbouring India, with a similar caste system and an adherence to marriages within the caste, can provide a glimpse into the situation as it might be in Nepal.

e caste system has persisted in Indian Hindu society for around 3500 years. Like the $\mathrm{Y}$ chromosome, caste is de ned at birth, and males cannot change their caste.. Studies on 
predominance of a single cluster of haplotypes in India con $\mathrm{rm}$ the genetic isolation and dri within the Jaunpur upper castes which are likely to result from founder e ects and social factors. ${ }^{33}$ John Burdon Sanderson Haldane (1892-1964), one of the founders of population genetics, has commented in one of his essays that if intercaste marriages in India became common, various recessive characters will become rarer. ${ }^{34}$

Diagnosis, To begin with, the health community in Nepal needs to assess the importance of inborn errors of metabolism in terms of infant mortality, incidence of mental retardation due to IEMs, time and resources. An assessment of incidence of IEMs anywhere is di cult unless a screening system is in place. is is because most IEMs are di cult to diagnose unless being evaluated by someone trained in IEM diagnosis and care, so that most cases that go undiagnosed result in irreversible mental retardation or death. In a retrospective study on known cases of inborn errors of metabolism in a pediatric intensive care unit in India, 36\% of the infants expired, $45 \%$ improved and $36 \%$ progressed to sequelae. ${ }^{35}$ However, an initial a tempt at knowing the incidence of inborn errors in Nepal can be made by screening known cases of mental retardation. is can be done by a series of simple biochemical tests on blood and urine. Such tests were developed over a period of years and have been used for diagnosis since 1962..$^{36}$ In 1972, Guthrie and his colleagues extended their Phenylketonuria test to a multiple screening program for several inborn errors of metabolism. ${ }^{37}$ ese tests can be carried out in a biochemical laboratory using coloring agents, paper chromatography and enzymatic methods. ${ }^{38,39}$

Once an estimate of the number of cases of mental retardation resulting from inborn errors of metabolism are known, an informed decision can be made about whether screening newborns for IEMs to calculate the incidence per 1000 newborns would be economically and ethically feasible. is would also need to take into account the known number of cases where there were the classic symptoms of metabolic encephalopathy in the newborn followed by death. A regular screening programme to screen for metabolicdisorders prevalent in Nepal will meet the criteria set by the Wilson's and Jungner ${ }^{40}$ principles of screening for disease. ese principles state that

e condition sought should be an important health problem to the individual and /or the community: So far, the focus of various health organizations in Nepal has been on infectious diseases so that diseases causing disabilities have taken a backseat. e problem, when occurring in an individual is devastating to the family as well as to the child anywhere, and not just in Nepal. ere should be an accepted treatment for patients with recognized disease. It is axiomatic that case nding should only be undertaken when the prospects for treating the condition are at least reasonable. - Most inborn errors of metabolism are treatable with changes in diet.

e knowledge and skill for treating inborn errors of metabolism is negligible in Nepal. A system to begin training individuals for tackling IEMs should be initiated as soon as possible.

Facilities for diagnosis and treatment should be available: Diagnosis can be carried out with simple biochemical tests. However, treatment, as mentioned above, will require education and training.

ere should be a recognized latent or early symptomatic stage: Most symptoms resulting from an inborn error of metabolism are recognizable as soon as they occur in the newborn.

ere should be a suitable test or examination: ese biochemical tests were in use for screening in UK and US in the 1960s for screening procedures, and hence quite reliable in showing a low false-negative rate. e test should be acceptable to the population: Most of these biochemical tests are carried out on urine, which should be acceptable to the population.

e natural history of the condition should be adequately understood: All inborn errors are adequately understood to provide treatment.Inherited metabolic conditions have greatly bene ted from recent biomedical advances. e Human Genome Project has increased understanding of complex biological systems and provides an unprecedented boost to our knowledge of the molecular details of inborn metabolic disorders.

ere should be an agreed policy on whom to treat as patients( to be tested)

e costs of case nding should be economically balanced in relation to possible expenditure on medical care as a whole: Case nding using simple biochemical tests will be far cheaper than providing for and treating a retarded child, or facing the devastating e ect of losing a child on a family. Case nding should be a continuous process and not a "once and for all" project. ( to be tested)

\section{TREATMENT}

It is widely held in Nepal that inborn errors of metabolism are not treatable. is misconception might also be responsible for the hesitation on the part of medical professionals in pursuing the diagnosis of these conditions. Older, but quite e ective methods of treatment of 
IEMs require dietary management in order to restrict the formation of or accelerate the removal of the toxic metabolite. Administration of vitamins helps increase the activity of certain enzymes responsible for a particular metabolic disease. Advances in biotechnology have made it possible to produce in laboratories the actual enzymes that are de cient in order to administer them to patients. ${ }^{41}$ ere are also new strategies in development, involving, for example, recovery of residual enzyme activity using chaperones, cell therapy and gene therapy and also combination treatments. A detailed description of treatment of di erent types of inborn errors is beyond the scope of this article. e reader is referred to some reviews for further reading on treatment of inborn errors of metabolism. ${ }^{41,42}$

\section{CONCLUSIONS}

Keeping in view the incidence of mental retardation, prevalence of consanguinity in some areas of Nepal and marriage within a particular caste, it is prudent to assume that there are substantial cases of inborn errors of metabolism occurring in Nepal, which remain undiagnosed due to a lack of concern towards this group of disorders. e results of these disorders are either irreversible retardation or death, both of which are devastating to any family, rich or poor. Studies to gauge the burden of this group of disorders on Nepalese society are in order. Simultaneously, biochemists and pediatricians need to be trained in the diagnosis and treatment of inborn errors by way of preparation to be ready when such cases are encountered.

\section{RECOMMENDATION}

It is time for Nepal health professionals and authorities to consider the possibility of existence of inborn errors of metabolism in the Nepalese population. In order to gauge the prevalence of metabolic disease, existing cases of mental retardation should be tested biochemically for the presence of known metabolites of IEMs. A true scenario however can only be obtained on screening newborns all over Nepal. An initiative should be be taken in Kathmandu using simple biochemical methods. For this purpose biochemists and pediatricians need to be trained in the eld of metabolic disease in order to have an established system so that the possibility of early diagnosis and intervention is enhanced. 


\section{REFERENCES}

1. Polli + RJ, Leonard JV, Green A, Nicholl J, McCabe CJ, Nicholson P, Booth A, Tunaley JR, Cooper NJ, Virdi NK. Neonatal screening for inborn errors of metabolism: cost, yield and outcome. Health Technology Assessment 1997; $1(7)$.

2. Sanderson S, Green A, Preece MA, et al. e incidence of inherited metabolic disorders in the West Midlands, UK. Arch Dis Child 2006;91:896-9.

3. Rama Devi AR and Naushad SM.Newborn Screening in India: Symposium on clinical genetics. Indian J Pediatr 2004; $71: 157-160$

4. Satwani H, Raza J, Hanai J, Nomachi S. Prevalence of selected disorders of inborn errors of metabolism in suspected cases at a Tertiary Care Hospital in Karachi. J Pakistan Medical Association 2009;59:815-819.

5. Han LS, Ye J, Qiu WJ, Gao XL, Wang Y, Jin J, et al. Diagnosis of inborn errors of metabolism using tandem mass spectrometry and gas chromatography mass spectrometry Zhonghua Yi Xue Za Zhi 2008;88:2122-6.

6. Manandhar K and Manadhar, DS. A case report of Wilson's disease Kathmandu Univ Med J 2003;1:38-41.

7. Gurubacharya SM and Gurubacharya RL Atypical Presentation of Wilson's Disease. J Nepal Paediatr Soc 2008;28:66-7.

8. Shrestha U, Bha tacharya S, Bha $\uplus_{a}$ NK, Jha CB.Cytogenetic analysis of children with suspected genetic disorder. Kathmandu Univ Med J 2009; 7:40-43.

9. Majhi S, Mishra A, Mehta KD, Baral N, Shrestha P.Detection of beta-thalassemia (homozygous) by hemoglobin electrophoresis on agar gel and citrate agar medium: a case report. Nepal Med Coll J 2007;9:70-1.

10. Cha terjea JB.Haemoglobinopathies, Glucose-6-phosphate Dehydrogenase De ciency and Allied Problems in the Indian Subcontinent. Bull Wld Hlth Org 1966;35:837-56.

11. Burton B. Inborn Errors of Metabolism in infancy: A guide to Diagnosis. Pediatrics 1998;102:e69.

12. Shih VE. Introduction and summary of clinical ndings in inborn errors of metabolism. In: Shih VE, editor. Laboratory techniques for the detection of hereditary metabolic disorders. Boca Raton, Fl rida: CRC Press; 1973. p.1-10.

13. Synnes AR. Use of the laboratory in prediction of outcome in the high-risk newborn. Clinical Chemistry 1997;43:243-8.

14. Blau N, Blaskovics ME, Duran M. Simple tests in urine and blood. In: Blau N, Blaskovics ME, Duran M, editors. Physician's guide to the laboratory diagnosis of metabolic diseases. London: Chapman \& Hall Medical; 1996. p.3-11.

15. Enns GM and Packman S. Diagnosing Inborn Errors of Metabolism in the Newborn: Laboratory Investigations. Neoreviews 2001;2:192.
16. Wilcken B, Wiley V, Hammond J and Carpenter K. Screening Newborns for Inborn Errors of Metabolism by Tandem Mass Spectrometry N Engl J. Med 2003;348:23.

17. Karkee R, Yadav BK, Chakravar ${ }^{y}$ A, Shrestha DB. e prevalence and characteristics of disability in Eastern Nepal. Kathmandu Univ Med J 2008;6:94-7.

18. h $४$ p://www.searo.who.int/ UNICEF Nepal. A situational analysis of disability in Nepal. United Nations Children's Fund, Nepal and His Majesty's Government Nepal, National Planning Commission; Kathmandu; 2001.

19. VaRG, A situation analysis of disabilities in Nepal, phase -1 by Valley Research Group, 1996 Mar.

20. Upadhyaya $\mathrm{KD}$ and Pol, K. A mental health prevalence survey in two developing towns of western region. J Nepal Med Assoc 2003;42:328-30.

21. Jha A.Nepalese psychiatrists' struggle for evolution . Psychiatric Bulletin 2007;31: 348-50.

22. Rao AN, Koch M, Kavitha J, Ghosh S, Kumar SV.Consanguinity and inborn errors of metabolism- an early impression. Perinatology 2008; 10:75-83.

23. Fricke T, Axinn AG and ornton A. Marriage, social inequality and women's contact with their natal families in alliance societies: Two Tamang examples. American Anthropologist 1993; 95:395-419.

24. Fricke T. Marriage change and moral change: culture, value and demographic transition. Paper presented at the conference on " e Continuing Demographic Transition: e J. C. Caldwell Seminar”, 14-17 August, Canberra,1995.

25. Kumar D (Editor) Genetic disorders of the Indian subcontinent. [Place Unknown]: Kluwer Academic Publishers; 2004. p.127.

26. Vaidya TR, Manandhar T, Joshi SL.Social History of Nepal. New Delhi: Anmol Publications;1993. p.61.

27. Reich D, angaraj K, Pa terson N, PriceAL and Singh L. Reconstructing Indian population history. Nature 2009;461:489-95.

28. Joshi BL, Leo ER. Democratic Innovations in Nepal: A Case Study of Political Acculturation. Berkeley: University of California Press; 1966.

29. Gayden T, Cadenas AM, Regueiro M, Singh NB, Zhivotovsky LA, Underhill PA, Cavalli-Sforza LL, and Herrera RJ. e Himalayas as a Directional Barrier to Gene Flow.Am J Hum Genet 2007;80: 884-94.

30. Sharma PR. Caste, Social mobility and Sanskritization: State and Society in Nepal. Nepal: Himal Books; 2004. p.129.

31. Berreman GD. Hindus of the Himalayas. [Place Unknown]: University of California Press; 1972. p.198.

32. Quigley D. Introversions and Isogamy: Marriage pa terns of the Newars of Nepal. Indian Sociology 1986;20:75-95. 
33. Zerjal, T. et al. Y-chromosomal insights into the genetic impact of the caste system in India. Hum. Genet 2007;121:137-144.

34. HaldaneJBS, Reprints and Re ections- A defense of Beanbag genetics. International Journal of Epidemiology 2008;37:435-42.

35. Kamate M, Chetal V, Kulgod V, Patil V and Christopher R. Pro le of Inborn Errors of Metabolism in a Tertiary Care Centre PICU. Indian J Pediatr 2010; 77:57-60.

36. Berry, H. K. Detection of metabolic disorders among mentally retarded children by means of paper spot tests. Amer. J. Ment. Defic 1962;66:555-60.

37. Murphey WH, Patchen L, Guthrie R Screening tests for argininosuccinic aciduria, orotic aciduria, and other inherited enzyme de ciencies using dried blood specimens Biochem Genet 1972 ;6:51-9.
38. Buist NRM. Set of Simple Side-room Urine Tests for Detection of Inborn Errors of Metabolism. Brit. Med. J 1968;2:745-9.

39. Boggs DE. Detection of Inborn Errors of Metabolism, Critical Reviews in Clinical Laboratory Sciences. [Journal Unknown] 1971:529-72.

40. Wilson JMG, Jungner F. Principles and Practice of Screening for Disease. Public Health Papers, No. 34. Geneva, Switzerland: World Health Organization. 1968:26-39.

41. Schwartz IV, de Souza CF, Giugliani R. Treatment of inborn errors of metabolism. J Pediatr (Rio J) 2008;84(4 Suppl):S8-19.

42. Kabra M. Dietary Management of Inborn Errors of Metabolism. Indian J Pediatr 2002;69:421-6. 